\title{
Rehmannia glutinosa polysaccharide liposome as a novel strategy for stimulating an efficient immune response and their effects on dendritic cells
}

This article was published in the following Dove Press journal:

International Journal of Nanomedicine

14 December 2016

Number of times this article has been viewed

\author{
Yee Huang' \\ Tao Qin ${ }^{2}$ \\ Yifan Huang ${ }^{2}$ \\ Zhenguang Liu' \\ Ruonan Bo' \\ Yuanliang $\mathrm{Hu}^{\prime}$ \\ Jiaguo Liu' \\ YiWu' \\ Deyun Wang ${ }^{1,2}$ \\ 'College of Veterinary Medicine, \\ Institute of Traditional Chinese \\ Veterinary Medicine, College of \\ Veterinary Medicine, Nanjing \\ Agricultural University, Nanjing, \\ ${ }^{2}$ College of Animal Science and \\ Veterinary Medicine, Fujian \\ Agriculture and Forestry University, \\ Fuzhou, People's Republic of China
}

Correspondence: Deyun Wang Institute of Traditional Chinese Veterinary Medicine, College of Veterinary Medicine, Nanjing Agricultural University, Nanjing 210095 , People's Republic of China

Tel +862584395203

Fax +86 2584398669

Email dywang@njau.edu.cn

\begin{abstract}
Nanomedicine, the medical application of nanotechnology, promises a seemingly limitless range of applications from drug delivery to adjuvants and therapeutics. Our current research is focused on natural polymer-based liposome adjuvants. With the aim of inducing protective and long-lasting immunity, the immunological adjuvant activity of Rehmannia glutinosa polysaccharide liposome (RGPL) was investigated. In vivo, the splenic lymphocyte proliferation ratios and ovalbumin-specific immunoglobulin G titers of ovalbumin-RGPL-vaccinated mice were significantly upregulated. In draining lymph nodes, the expression of $\mathrm{MHC} \mathrm{II}^{+} \mathrm{CD} 11 \mathrm{c}^{+}$and $\mathrm{CD} 86^{+} \mathrm{CD} 11 \mathrm{c}^{+}$was increased by RGPL; in addition, the percentages of central memory cells $\left(\mathrm{T}_{\mathrm{CM}}\right)$ and effector memory cells $\left(\mathrm{T}_{\mathrm{EM}}\right)$ were also elevated. RGPL could effectively provide adequate antigen exposure in lymph nodes. In vitro, RGPL could promote dendritic cell maturation and enhance dendritic cell functions, such as the mixed lymphocyte reaction and antigen presentation. Overall, the results demonstrated that RGPL has the potential to act as an effective controlled release vaccine adjuvant.
\end{abstract}

Keywords: Rehmannia glutinosa polysaccharide liposome, adjuvant, controlled release, ovalbumin, dendritic cells

\section{Introduction}

Vaccines play an important role in controlling a substantial proportion of animal morbidity and mortality, particularly in the food-producing industries. With the development of modern vaccines, the creation of more efficacious adjuvants is imperative for the successful induction of adequate immune responses. Aluminum-containing adjuvants, the most widely used vaccine adjuvants, generally induce a good antibody response and are relatively inexpensive. ${ }^{1,2}$ However, they are ineffective in inducing a cell-mediated immune response, can have a detrimental effect on the stability of vaccine antigens, and are associated with local adverse vaccine reactions. In addition, aluminum is not biodegradable..$^{3,4}$

At the same time, natural polymers such as polysaccharides have been widely studied as safe and potent alternative adjuvants, which can effectively strengthen the primary and the adaptive immune responses, and as a consequence increase the efficacy of vaccines. ${ }^{5,6}$ Rehmannia glutinosa polysaccharide (RGP), one of the active components of $R$. glutinosa, was shown to exert strong immunomodulatory properties. ${ }^{7,8}$ However, RGP also has disadvantages when directly used for clinical purposes, such as being rapidly metabolized, having a short duration of action, a nonfocused scope of action and extensive clinical usage, among others. Thus, improving the bioavailability of RGP in clinical applications is of great importance. 
Over the past 20 years, there has been increasing interest in using nanoparticles as adjuvants. ${ }^{9,10} \mathrm{~A}$ number of approved nano-sized vaccine and drug-delivery systems highlight the revolution in disease prevention and treatment. ${ }^{11,12}$ Our recent research incorporated the herbal active ingredient within liposome. The lipid-based nanoparticle delivery system has shown properties that are fundamental for the development of modern vaccine formulations. Liposomes are enclosed spherical vesicles organized in one or several concentric phospholipidic bilayers and have been the subject of intensive investigations as drug and vaccine carriers due to their ability to encapsulate a wide range of bioactive either within the aqueous core or integrated within the lipid bilayer. ${ }^{13,14}$

Currently, at least eight liposome-based adjuvant systems are approved for human use or are undergoing clinical evaluation. ${ }^{15}$ The success of liposome-based adjuvant systems and increasing interest in their development can be attributed to their versatility and plasticity. Antigens can be attached to the liposome surface either by adsorption or stable chemical linking. Liposomal carrier provides adjuvant activity by enhancing antigen delivery or by activating innate immune response. ${ }^{16}$

In our previous experiments, RGP liposomes (RGPLs) significantly improved splenic lymphocyte proliferation. ${ }^{17}$ In this study, further investigations were made to uncover the mechanism of this more effective immunological enhancement by RGPL. The physical features of the RGPL that made them an attractive candidate for an adjuvant were investigated. Moreover, direct comparison of the immune stimulating capacity of RGPL was undertaken both in vivo and in vitro. Our results demonstrated that, in vivo, RGPL could effectively generate sustained cellular and humoral responses, as well as immunological memory. RGPL also strengthened vaccine potency in terms of elevating the expression of $\mathrm{MHC} \mathrm{II}^{+} \mathrm{CD} 11 \mathrm{c}^{+}$and $\mathrm{CD} 86^{+} \mathrm{CD} 11 \mathrm{c}^{+}$. By providing controlled release, encapsulation in liposomes offered protection against degradation, and this resulted in a prolonged action time for RGP. In vitro, RGPL could also stimulate the maturation of dendritic cells (DCs) and enhance the function of mature DCs.

\section{Materials and methods Preparation and characterization of RGPLs}

Liposomes with RGP (purchased from Shanxi Ciyuan Biotechnology Co. Ltd) were prepared as described previously. ${ }^{17}$

Briefly, appropriate amounts of soybean phospholipid, cholesterol, and Twain-80 (40:5:4, mass ratio) were dissolved with chloroform and methanol. After evaporation, the remaining lipid film was dissolved by ethyl ether to obtain a liposomal dispersion. RGP solution was injected into the lipid solution. The resulting mixture was homogenized using an ultrasonic cleaner in ice water to form a stabile W/O emulsion. Followed by hydration with phosphate-buffered saline (PBS, pH 7.4) and 20-min sonication (JY92-II DN, Xinzhi Bio-technology and Science Inc.) to form the uniform liposome. Ultimately, the solution was successively filtered using 0.45 and $0.22 \mu \mathrm{m}$ millipore membrane.

Encapsulation efficiency was determined as previously described. ${ }^{17}$ Briefly, separating the free drug with the encapsulated drug through centrifuge method. The RGP concentration was quantified by the vitriol-phenol method.

Particle size distribution ( $Z$-average) and polydispersity index (PDI) and zeta potential of the RGPL were determined using dynamic light scattering (Malvern Zetasizer 3000, Malvern, UK). Measurements were performed at $25^{\circ} \mathrm{C}$, and the results presented are the mean of three successive measurements of $100 \mathrm{~s}$ of at least three independent samples. Samples were diluted with PBS to adjust the signal level. The stability of RGPL within 30 days post preparation stored at room temperature was also investigated.

The liposome morphology was observed using H-7650 transmission electron microscope (Hitachi High-Technologies Corporation) after negative staining with $1 \%$ phosphotungstic acid. The presence of endotoxin in the studied liposomes and RGP was measured by the ToxinSensor ${ }^{\mathrm{TM}}$ Gel Clot Endotoxin Assay Kit from Genscript (Piscataway, NJ, USA). When the endotoxin amount was up to the standard of Chinese Veterinary Pharmacopoeia $(<0.5 \mathrm{EU} / \mathrm{mL})$, they were stored at $4^{\circ} \mathrm{C}$ for further test.

\section{In vitro antigen release study}

The in vitro antigen release analysis of RGPL was carried out in triplicate at 4 and $37^{\circ} \mathrm{C}$. One batch of ovalbumin (OVA)-loaded RGPL was divided into four groups, put into four separate Eppendorf tubes, and kept in incubators at 4 and $37^{\circ} \mathrm{C}$. At predetermined time intervals, the particles in one tube would be taken out and centrifuged. The amount of released antigen in the supernatant was detected by micro bicinchoninic acid assay (Pierce, Bartlesville, OK, USA). Blank liposomes (BL) were used as a control. The percentage of antigen remaining in the RGPL was calculated by the following formula:

OVA remaining $\%=1-\frac{\text { Amount of OVA released }}{\text { Total amount of OVA added }} \times 100$ 


\section{In vivo evaluation of the immunoenhancement efficacy of RGPL}

Animals and immunizations

The same quantity of female and male C57BL/6J mice (4-week old, weighing between 18 and $22 \mathrm{~g}$ ) were purchased from the Comparative Medicine Centre of Yangzhou University (Yangzhou, People's Republic of China) and acclimatized for 7 days prior to use. The experimental protocol involving animal subjects was approved by the university ethics committee for the humane care and use of experimental animals, and each mouse was used once and treated in accordance with the National Institutes of Health guidelines for the care and use of laboratory animals. All procedures involving animals were conducted strictly in accordance with the Chinese legislation for the use and care of laboratory animals, and the experimental use of animals and procedures were approved by the Nanjing Agricultural University Animal Care Committee.

Groups of mice received $0.5 \mathrm{~mL}$ of vaccine formulations containing $100 \mu \mathrm{g}$ of OVA mixed with liposomes $\left(\mathrm{RGPL}_{\mathrm{H}}, 2.0 \mathrm{mg}\right.$ of RGP $+20 \mathrm{mg}$ of lipid; $\mathrm{RGPL}_{\mathrm{M}}, 1.0 \mathrm{mg}$ of RGP $+20 \mathrm{mg}$ of lipid; RGPL, $0.5 \mathrm{mg}$ of RGP $+20 \mathrm{mg}$ of lipid; BL, $20 \mathrm{mg}$ of lipid; the encapsulation efficiency of OVA was $66.76 \% \pm 0.19 \%)$ or mixed with RGP $(2.0 \mathrm{mg})$, alum adjuvant, and BL (20 mg of lipid). Vaccine formulations were administered subcutaneously in the dorsal skinfold, and each mouse received vaccine on day 0 , with a boost on day 7. Mice of the blank control group were injected with PBS (0.5 mL/mouse, $\mathrm{pH}$ 7.4). Serum samples and splenic lymphocytes were collected at 1 week after the first vaccination, and six collections were made at 1 week intervals to determine the concentrations of immunoglobulin $\mathrm{G}$ ( $\mathrm{IgG})$, interleukin 4 (IL-4), interferon gamma (IFN- $\gamma$ ), and lymphocyte proliferation.

\section{In vivo proliferation of splenic lymphocytes}

Single-cell suspensions $2.5 \times 10^{6}$ cells $/ \mathrm{mL}$ with RPMI 1640 medium (Gibco, Invitrogen, Paisley, UK), 10\% fetal bovine serum (Gibco), and $100 \mathrm{IU} / \mathrm{mL}$ penicillin-streptomycin were obtained as previously described. ${ }^{18}$ The lymphocytes prepared from vaccinated mice were re-stimulated with $20 \mu \mathrm{L}$ of polyhydroxyalkanoate (PHA, $10 \mu \mathrm{g} / \mathrm{mL}$; Sigma, St. Louis, MO, USA), lipopolysaccharide (LPS; $5 \mu \mathrm{g} / \mathrm{mL}$; Sigma), or RPMI 1640 medium. After $44 \mathrm{~h}$ of incubation at $37^{\circ} \mathrm{C}, 30 \mu \mathrm{L}$ of MTT solution $(5 \mathrm{mg} / \mathrm{mL})$ was added to each well and incubation was continued for an additional $4 \mathrm{~h}$. The supernatant was removed and then the formazan salts formed were dissolved by $100 \mu \mathrm{L}$ of DMSO.
Absorbance was measured at $570 \mathrm{~nm}$ using an enzymelinked immunosorbent assay (ELISA) reader (EL 800; BIO-TEK, USA). The percentage growth (\% growth) was calculated according to the following equation:

$$
\% \text { growth }=\frac{A_{570}(\text { Mitogen })-A_{570}(\text { RPMI 1640 })}{A_{570}(\text { RPMI 1640 })} \times 100
$$

\section{Measurement of cytokines}

Serum samples were collected from peripheral blood and stored at $-80^{\circ} \mathrm{C}$ until use. The presence of IL- 4 and IFN- $\gamma$ in the serum samples was determined using the mouse IL-4 enzyme-linked immunosorbent assay (ELISA) set and IFN- $\gamma$ ELISA kits (BD Biosciences, San Jose, CA, USA) in accordance with the manufacturer's instructions.

\section{Measurement of OVA-specific IgG production in the serum of vaccinated mice}

Serum samples were inactivated at $56^{\circ} \mathrm{C}$ for $30 \mathrm{~min}$ before being added to $96-$ well ELISA plates (BD Biosciences). The plates were coated with $10 \mu \mathrm{g} / \mathrm{mL}$ OVA $(100 \mu \mathrm{L} /$ well $)$ and incubated overnight. Plates were then washed three times and PBS containing $10 \%(\mathrm{w} / \mathrm{v})$ bovine serum albumin was added $(150 \mu \mathrm{L} /$ well). The buffer was then discarded, and serum samples were added to the wells. Plates were incubated for $2 \mathrm{~h}$ at room temperature. After washing three times, ZyMax goat-antimouse IgG $(\mathrm{H}+\mathrm{L})$ horseradish peroxidase conjugate (Zymed) was added to each well and incubated at $37^{\circ} \mathrm{C}$ for $1 \mathrm{~h}$. Plates were washed again and then horseradish peroxidase substrate containing $1 \mu \mathrm{L} / \mathrm{mL}$ of $30 \%$ hydrogen peroxide was added. Plates were incubated at $37^{\circ} \mathrm{C}$ for $15 \mathrm{~min}$ in the dark. The reaction was stopped by the addition of Stop Reagent (Sigma). The absorbance was finally measured at a wavelength of $414 \mathrm{~nm}$.

\section{Immune activation in the lymph nodes (LNs)}

Expression of MHC II and co-stimulatory molecules on DCs in draining LNs

C57BL/6 mice $(n=4)$ were subcutaneously vaccinated as described in "Animals and immunizations" section. Popliteal LNs were harvested and processed into single-cell suspensions. Cells were stained with a mixture of antimouse antibodies (FITC-CD11c, PE-MHC II, and PE-cyanine5-CD86; all from eBioscience, USA). Expression of $\mathrm{MHC} \mathrm{II}^{+} \mathrm{CD} 11 \mathrm{c}^{+}$ and $\mathrm{CD} 86^{+} \mathrm{CD} 11 \mathrm{c}^{+}$on DCs was determined using BD FACSVerse (BD Biosciences, San Diego, CA, USA) and analyzed using Summit software (version 4.3.02). 


\section{Determination of memory T-cell responses in} draining LNs

C57BL/6 mice $(n=4)$ were subcutaneously vaccinated as described in "Animals and immunizations" section. Draining LNs were collected 7 days after the second immunization. Cell suspensions were stained with a mixture of antimouse antibodies (PE-CD4, PE cyanine5-CD44, APC-CCR7, and FITC-CD62L; all from eBioscience) to identify the percentage of memory $\mathrm{T}$ lymphocytes by flow cytometry, and the data were analyzed.

Determination of available antigen in draining LNs by an immunohistochemical method

$\mathrm{C} 57 \mathrm{BL} / 6$ mice $(\mathrm{n}=4)$ were subcutaneously vaccinated as described in "Animals and immunizations" section. Sciatic and popliteal LNs were isolated from the euthanized mice 2 and 7 days after the second immunization. Immunohistochemistry was performed on $4 \mu \mathrm{m}$ thick paraformaldehydefixed and paraffin-embedded tissue sections. Subsequent to deparaffinization, endogenous peroxidase activity was inhibited by incubating with $3 \% \mathrm{H}_{2} \mathrm{O}_{2}$ for $20 \mathrm{~min}$. Sections were blocked by goat serum and immunostained with antibody against OVA (LifeSpan BioSciences, Inc., Seattle, Washington, DC, USA). Secondary antibody from a PicTure-PV6000 kit (Zymed Laboratories Inc., South San Francisco, CA, USA) and diaminobenzidine (ZSGB-Bio, Beijing, People's Republic of China) was used for color development according to the manufacturer's instructions. Sections were then counterstained with hematoxylin for cell nucleus identification. Immunohistochemical micrographs were documented with an Olympus microscope.

\section{Analysis of the effect of RGPL on DCs}

\section{Generation of bone marrow-derived DCs}

Primary bone marrow DCs were obtained from mouse bone marrow precursors as previously described, ${ }^{8,19}$ with minor modifications. DCs were cultured at a starting concentration of $2.0 \times 10^{6}$ cells $/ \mathrm{mL}$ in round-bottomed 6-well plates with RPMI 1640 supplemented with 10\% FCS (Gibco, Waltham, MA, USA). Cells were cultured in a humidified chamber at $37^{\circ} \mathrm{C}$ and $5 \%$ atmospheric $\mathrm{CO}_{2}$. After incubation for $24 \mathrm{~h}$, the medium with nonadherent cells was replaced with RPMI 1640 medium supplemented with 10\% FCS, 20 ng/mL GM-CSF (R\&D; BJ2313011), and rmIL-4 (R\&D; BC612121). The culture medium was removed and replenished with an equal volume of fresh medium every 2 days. From day 6 onward, the nonadherent DCs were harvested and used for subsequent experiments. DCs were purified by positive selection with anti-CD11c MACS MicroBeads (Miltenyi Biotec, Bergisch Gladbach, Germany), following the manufacturer's protocol.

\section{Flow cytometry}

The effect of RGPL on the phenotype of DCs was examined using flow cytometry. The immature DCs were collected as described in "Generation of bone marrow-derived DCs" section. On the seventh day of incubation, RGPL, BL, RGP, serum-free RPMI 1640, or $5 \mu \mathrm{g} / \mathrm{mL}$ LPS was added to the DCs and incubated for another $48 \mathrm{~h}$. The mature DCs were collected and stained with PE-conjugated antimouse CD80 (B7-1), PE-conjugated antimouse CD86 (B7-2), and PE-conjugated antimouse MHC class II (I-A/I-E) antibodies. The mixture was incubated at $4^{\circ} \mathrm{C}$ for $30 \mathrm{~min}$ in the dark. Following washing with PBS twice, DCs were resuspended in $0.5 \mathrm{~mL} 1 \%$ paraformaldehyde. The percentages of CD 80 , CD86, and MHC class II were analyzed with an FACSCalibur (BD Pharmingen, San Diego, CA, USA).

\section{Analysis of the effect of RGPL on DC stimulation of mixed lymphocyte proliferation}

The immature DCs were collected as described in "Generation of bone marrow-derived DCs" section. On the seventh day of incubation, different concentrations of RGPL, serum-free RPMI 1640 , or $5 \mu \mathrm{g} / \mathrm{mL}$ LPS were added to the DCs and incubated for another $48 \mathrm{~h}$. After 30 min of treatment with $50 \mu \mathrm{g} / \mathrm{mL}$ mitomycin $\mathrm{C}$ at $37^{\circ} \mathrm{C}$, cells were washed with PBS twice and then resuspended in complete RPMI 1640 at a concentration of $5 \times 10^{5}$ cells $/ \mathrm{mL}$. Splenic lymphocytes from C57BL/6 mice were harvested as previously described. ${ }^{17}$ Splenic lymphocytes $\left(1.0 \times 10^{6}\right.$ cells $\left./ \mathrm{mL}\right)$ were cultured in 96-well plates in a volume of $100 \mu \mathrm{L} /$ well. The mature DCs were added in quadruplicate for each group. The cultures were incubated for $72 \mathrm{~h}$. In the last $4 \mathrm{~h}$ of incubation, MTT $(5 \mathrm{mg} / \mathrm{mL}$ and $30 \mu \mathrm{L} /$ well) was added into each well. The supernatant was then discarded prior to the addition of DMSO (100 $\mu \mathrm{L} /$ well). Finally, $A_{570}$ was determined as the index of DC stimulation of the proliferation of mixed lymphocytes.

\section{Assessment of the effect of RGPL on antigen presentation ability of DCs}

Mice were immunized subcutaneously with OVA solution (100 $\mu \mathrm{g}$ of OVA) mixed with aluminum adjuvant. On the 7th and 14th day, the mice were separately boosted. Three days after the last immunization, the responding cells were collected as described in "Analysis of the effect of RGPL on DC stimulation of mixed lymphocyte proliferation" 
section. Lymphocytes were resuspended in complete RPMI 1640 at a concentration of $1.0 \times 10^{6}$ cells $/ \mathrm{mL}$, supplemented with OVA $(100 \mu \mathrm{g} / \mathrm{mL})$, in 96-well plates. The DCs were treated as described in "Analysis of the effect of RGPL on DC stimulation of mixed lymphocyte proliferation" section. The DCs, having been treated with mitomycin C, were added to the lymphocytes in quadruplicate for each group. The cultures were incubated for $72 \mathrm{~h}$. In the last $4 \mathrm{~h}$ of incubation, MTT was added into each well. Thereafter, the supernatant was discarded before DMSO was added. Finally, the $A_{570}$ was tested as the index of the antigen presenting ability of the DCs.

\section{Statistical analysis}

Data were expressed as mean \pm standard errors (SEs). Duncan and LSD multiple range tests were used to determine the difference among groups. $P$-values of $<0.05$ were considered to be statistically significant.

\section{Results}

\section{Physical properties of RGPL}

The advantages of liposomes are based on the physical features of this novel delivery system. ${ }^{20}$ In this study, liposome morphology was observed through an H-7650 transmission electron microscope (Figure 1A and B). The RGPL presented as spherical particles of uniform size dispersed in the solute.

The particle sizes and PDI value of liposomes, either coencapsulated with RGP and OVA or encapsulated with RGP alone (RGPL) or antigen alone (BL-OVA), were all included for comparison (Figure $1 \mathrm{C}$ and $\mathrm{D}$ ). The mean particle size of the RGPL (170.83 $\pm 2.08 \mathrm{~nm})$ was slightly increased after

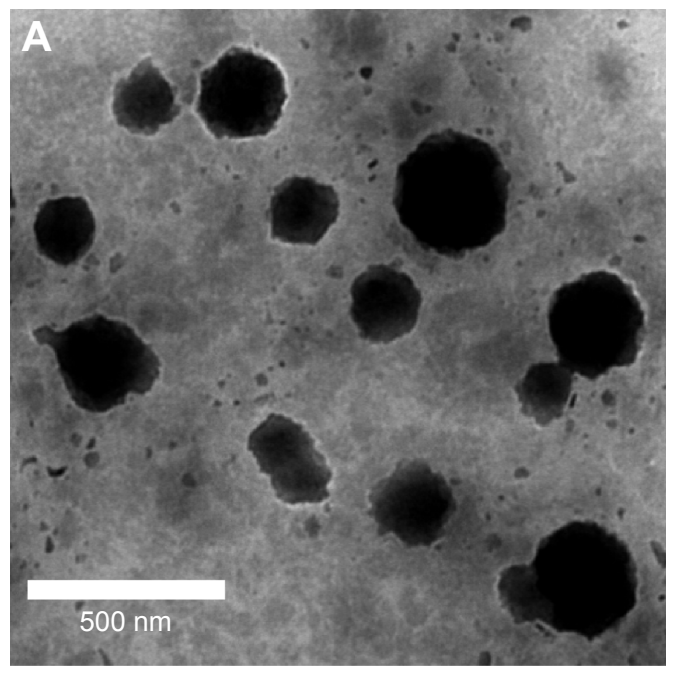

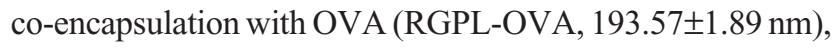
whereas that of BL was hardly changed after co-encapsulated with OVA. As for PDI value, RGPL-OVA and BL-OVA were lower than RGPL and BL, respectively. During the 30 days, the particle size of RGPL was increased by $94.6 \mathrm{~nm}$, from 170.8 to $265.4 \mathrm{~nm}$, whereas that of RGPL-OVA only increased by $66.8 \mathrm{~nm}$, from 193.6 to $260.3 \mathrm{~nm}$. Changes of BL-OVA and BL were nearly the same, both of which were a little bit $>100 \mathrm{~nm}$. As for the changes of PDI, small-scale fluctuations were presented by all the four groups. Besides, RGPL co-encapsulated with PCV-2 antigen also showed similar results, ${ }^{18}$ which further validated that the stability RGPL was not antigen specific.

To further determine the stability of RGPL, OVA release within 44 days was investigated (Figure 1E). Under the same temperature, OVA's remaining percentage of RGPL was higher than that of BL, which may indicate that liposomes encapsulating with RGP contribute to stability of RGPL. For the same RGPL under different storage temperatures, the percentages just presented minor changes in the first $20 \mathrm{~h}$, afterward, they both dropped significantly. In the first $20 \mathrm{~h}$, OVA's remaining percentage under $37^{\circ} \mathrm{C}$ was higher, while during 20th to 44 th $\mathrm{h}$, it was much lower than that under $4^{\circ} \mathrm{C}$. So for long time storage, $4^{\circ} \mathrm{C}$ is better than $37^{\circ} \mathrm{C}$.

\section{RGPL promote splenic lymphocyte proliferation}

The spleen represents an important and convenient lymphoid organ for studying the complex interplay between cells of the innate and adaptive immune response. ${ }^{21}$ Splenic lymphocytes are important for the immunological response in an organism,

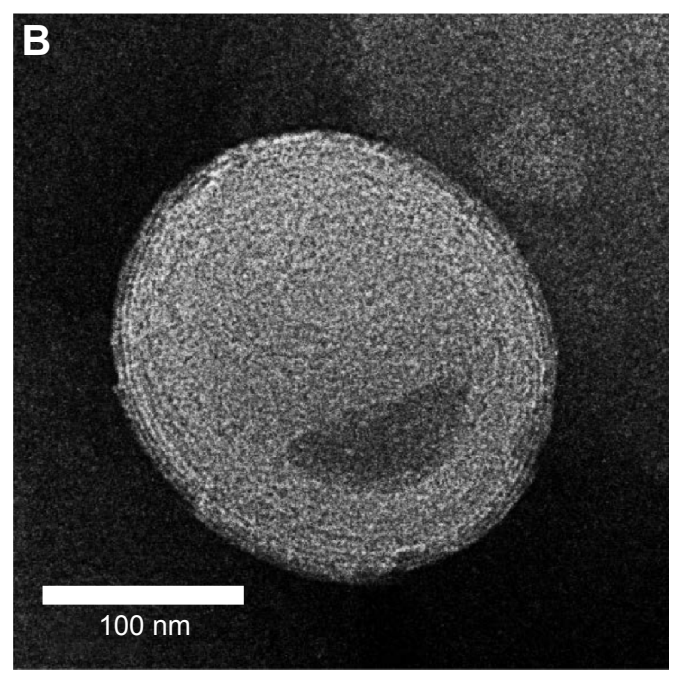

Figure I (Continued) 

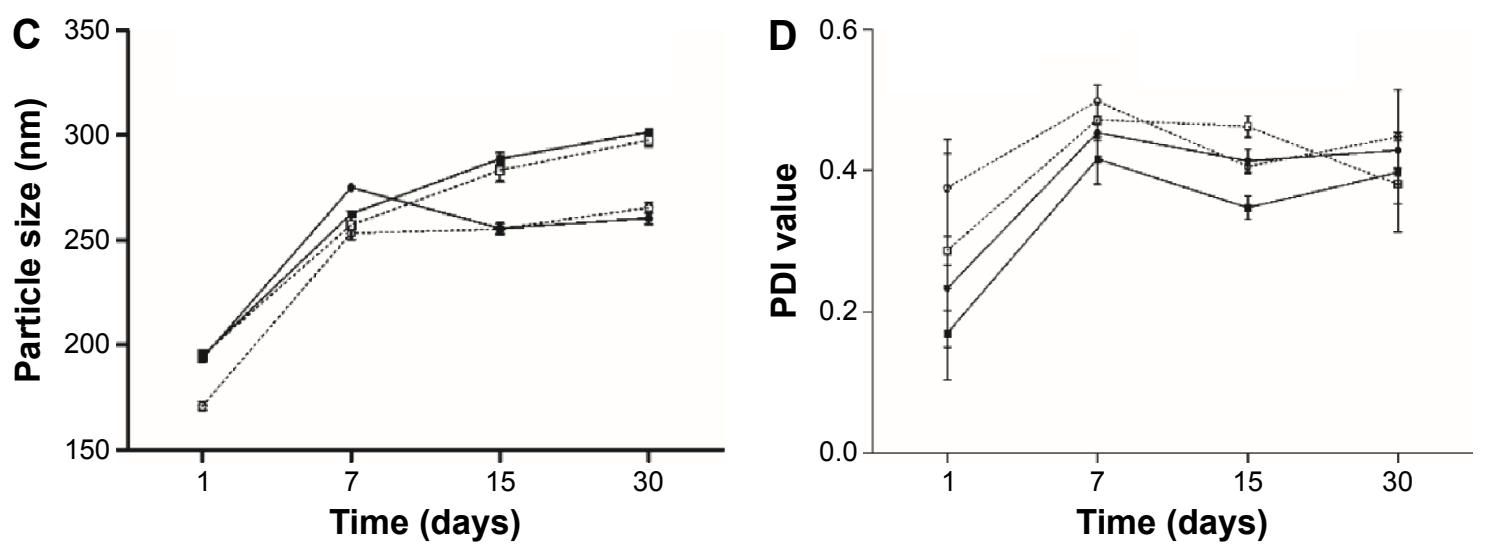

- RGPL-OVA $\rightarrow$ BL-OVA $\cdots \bullet$ RGPL $\cdots$ - B BL

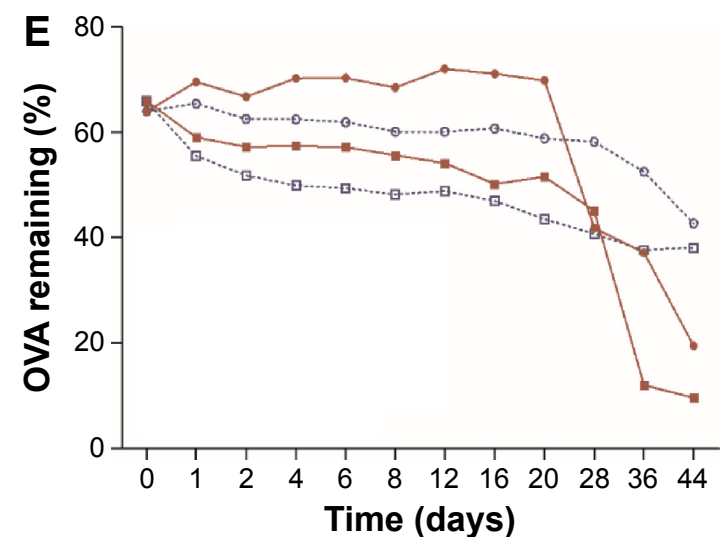

$\cdots 0 \cdots \operatorname{RGPL}\left(4^{\circ} \mathrm{C}\right) \cdots \boxminus \mathrm{BL}\left(4^{\circ} \mathrm{C}\right) \rightarrow \operatorname{RGPL}\left(37^{\circ} \mathrm{C}\right) \rightarrow-\mathrm{BL}\left(37^{\circ} \mathrm{C}\right)$

Figure I Physical characterization and in vitro release profiles of RGPL.

Notes: (A) Transmission electron microscope photograph of homodispersed RGPL $(\times 7,000)$. (B) Transmission electron microscope photograph of a single liposome of RGPL $(\times 30,000)$. (C) Particle sizes of RGPL and RGPL co-encapsulated with OVA. (D) PDI values of RGPL and RGPL co-encapsulated with OVA. (E) Release of OVA from RGPL. Mean of three independent experiments.

Abbreviations: BL, blank liposomes; OVA, ovalbumin; PDI, polydispersity index; RGPL, Rehmannia glutinosa polysaccharide liposome.

and the proliferation of splenic lymphocytes is the most immediate index reflecting organic immunity. ${ }^{22}$ In order to investigate the role of RGPL in immunological enhancement, the effect on LPS/PHA-stimulated splenic lymphocyte proliferation in immunized mice was examined.

The effects of RGPL on LPS/PHA-stimulated splenic lymphocyte proliferation in mice immunized with OVA are shown in Figure 2A and B. For the whole inoculation period (from the first to sixth week), the splenic lymphocyte proliferation ratios of RGPL groups were significantly higher than those generated with the RGP, BL, and alum groups $(P<0.05)$.

As shown in Figure 2A, the splenic lymphocyte proliferation ratio of the $\mathrm{RGPL}_{\mathrm{H}}$ group synergistically stimulated with LPS was significantly higher $(P<0.05)$ than the ratios for the $\mathrm{BL}$ and alum groups during the first 3 weeks. Interestingly, in the next 3 weeks, the ratio for the $\mathrm{RGPL}_{\mathrm{L}}$ group was significantly higher $(P<0.05)$ than the ratios for the other groups. As shown in Figure 2B, the splenic lymphocyte proliferation ratio of mice vaccinated with OVA and $\mathrm{RGPL}_{\mathrm{H}}$ and synergistically stimulated with PHA was significantly higher than the ratios for the other six groups during the 6 weeks investigated.

\section{Analysis of OVA-specific $\lg G$ production in the serum of vaccinated mice}

The production of OVA-specific IgG was determined using ELISA to assess the humoral response (Figure 3A). RGPL containing OVA was significantly more effective at inducing a humoral response when compared with RGP containing OVA $(\mathrm{n}=6, P<0.05)$ at all the time points investigated. The production of OVA-specific IgG in the $\mathrm{RGPL}_{\mathrm{H}}$ group was the highest at the most time points (from the second week to the sixth week) and was about 1.5 -fold higher than for the RGP group. Moreover, the antibody titers obtained from mice immunized with OVA-RGPL were significantly higher than for OVA-alum mice. Similar data also got on PCV-2 antigen, which showed that RGPL co-encapsulated with 

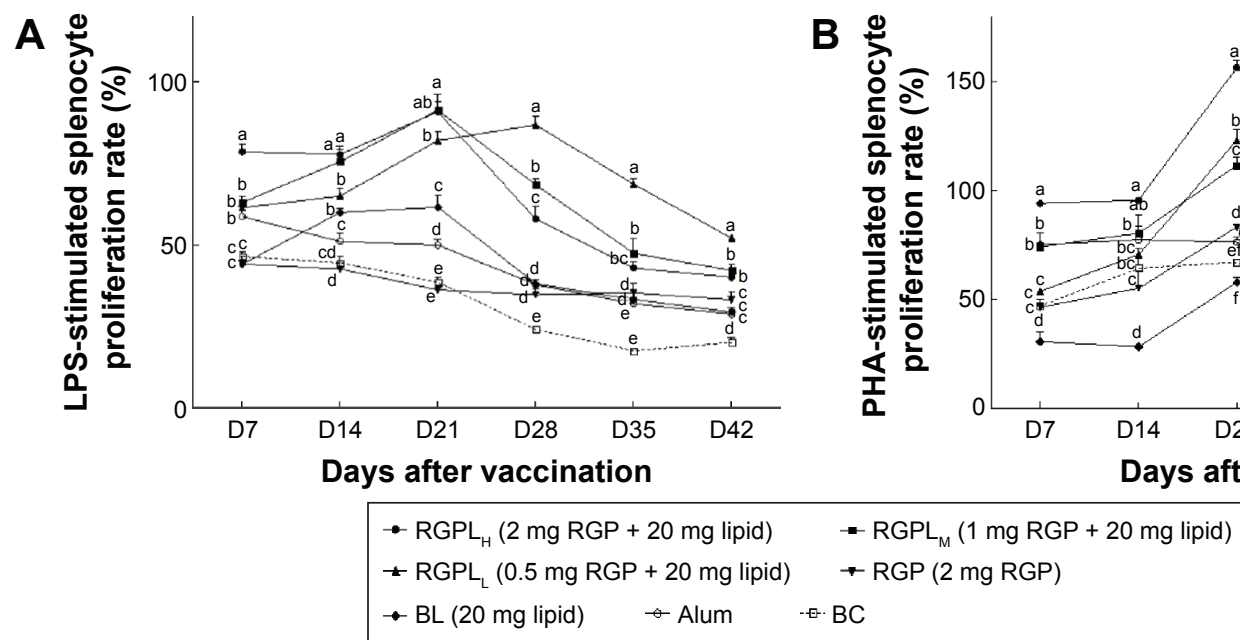

Figure 2 Proliferation rate of splenic lymphocytes harvested from vaccinated mice and re-challenged in vitro with LPS/PHA.

Notes: The proliferation rate of LPS-stimulated splenocyte (A) and PHA-stimulated splenocyte (B) were investigated on Day 7, I4, 2I, 28, 35, and 42 after first vaccination. a-e Marks that do not share the same letter in the same day differ significantly between groups. Mice were subcutaneously injected with vaccine formulations containing $100 \mu g$ of OVA and RGPL (4.0, 2.0, and I.0 mg/mL), RGP $(4.0 \mathrm{mg} / \mathrm{mL})$, aluminum adjuvant or BL in $0.5 \mathrm{~mL}$ volume, and each mouse received two doses at intervals of I week. Mice in the $B C$ group were injected with PBS. Splenic lymphocytes were collected at I-6 weeks after the first vaccination. The proliferation rates shown are mean \pm standard errors ( $\mathrm{n}=4$ ). Abbreviations: BC, blank control; BL, blank liposomes; LPS, lipopolysaccharide; OVA, ovalbumin; PBS, phosphate-buffered saline; PHA, polyhydroxyalkanoate; RGP, Rehmannia glutinosa polysaccharide; RGPL, Rehmannia glutinosa polysaccharide liposome.
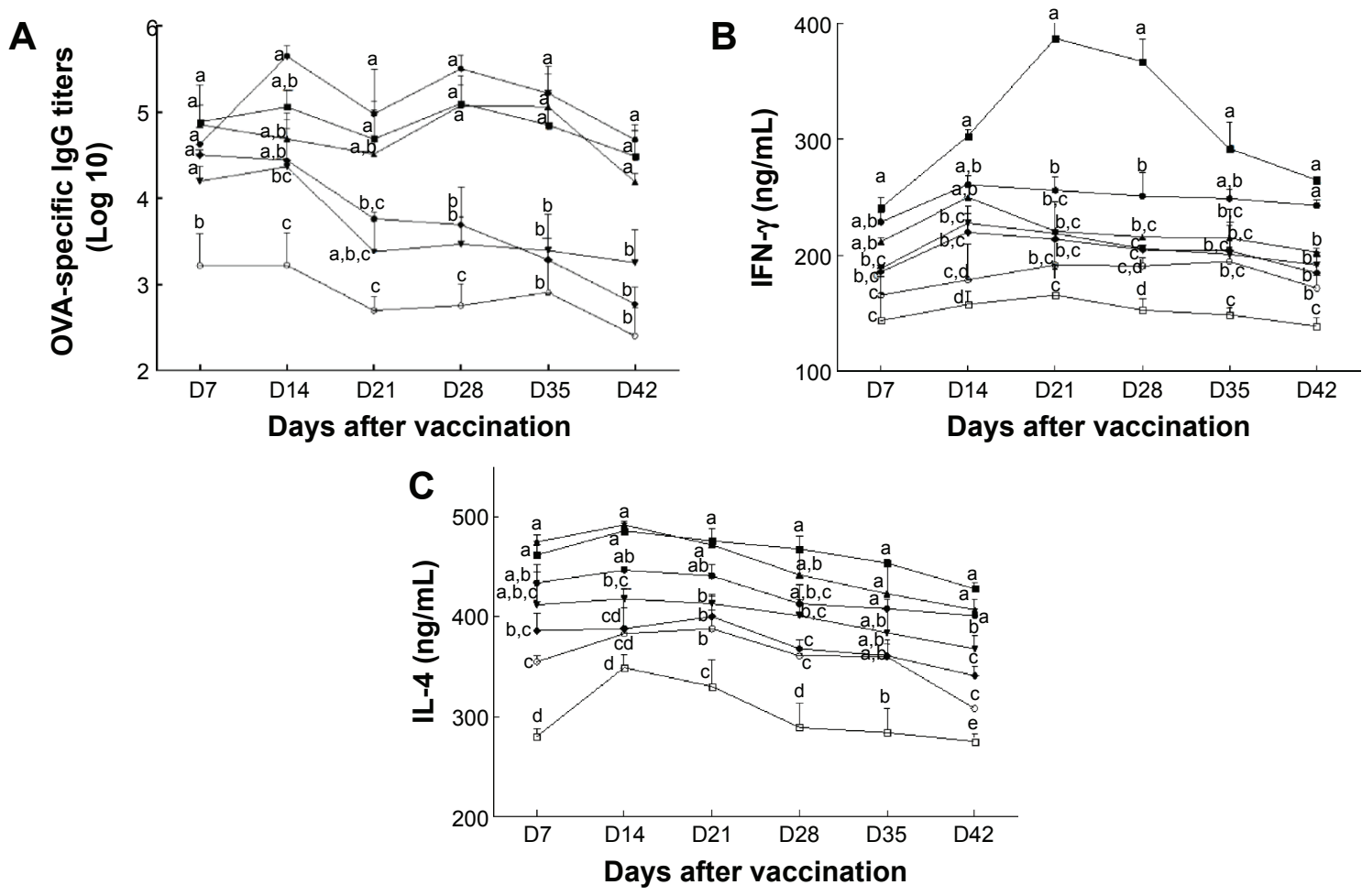

$\begin{array}{ll}\rightarrow \mathrm{RGPL}_{\mathrm{H}}(2 \mathrm{mg} \mathrm{RGP}+20 \mathrm{mg} \text { lipid }) & -\mathrm{RGPL}_{\mathrm{M}}(1 \mathrm{mg} \mathrm{RGP}+20 \mathrm{mg} \text { lipid }) \\ \leftarrow \mathrm{RGPL}_{\mathrm{L}}(0.5 \mathrm{mg} \text { RGP }+20 \mathrm{mg} \text { lipid }) & \rightarrow \mathrm{RGP}(2 \mathrm{mg} \text { RGP }) \\ \rightarrow \mathrm{BL}(20 \mathrm{mg} \text { lipid }) & \leftarrow \text { Alum }\end{array}$

Figure 3 Changes in OVA-specific IgG levels and cytokine production of mice immunized with RGPL, RGP, aluminum adjuvant, and BL containing I00 $\mu g$ of OVA.

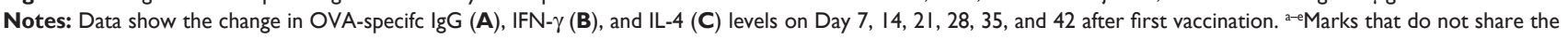
same letter in the same day differ significantly between groups. Each mouse received two doses at intervals of I week. Mice of the BC group were injected with PBS. Serum was collected at I-6 weeks after the first immunization. OVA-specific IgG and cytokine levels were estimated by ELISA. Data show the change in OVA-specific IgG, IL-4, and IFN- $\gamma$ levels after immunization. Bars depict the significant difference from the respective control groups tested on the same day $(n=6, P<0.05)$.

Abbreviations: BC, blank control; BL, blank liposome; ELISA, enzyme-linked immunosorbent assay; IFN- $\gamma$, interferon gamma; IgG, immunoglobulin G; IL-4, interleukin 4; OVA, ovalbumin; PBS, phosphate-buffered saline; RGP, Rehmannia glutinosa polysaccharide; RGPL, Rehmannia glutinosa polysaccharide liposome. 
PCV-2 significantly elevated levels of PCV-2-specific IgG. ${ }^{18}$ During the experiments, none of the mice showed any signs of local irritation or systemic discomfort.

\section{Analysis of cytokine production}

To a certain extent, IFN- $\gamma$ and IL-4 reflect the basic status of the cellular immunity and humoral immunity of an organism. ${ }^{23,24}$ In order to compare the ability of RGPL with that of RGP in inducing immune responses, the serum levels of IFN- $\gamma$ and IL-4 were measured by ELISA. In all samples, the highest levels of IFN- $\gamma$ and IL-4 were both seen in RGPL groups at all the time points investigated (Figure 3B and C). The production of IL-4 was enhanced during the first 3 weeks of the experiment and diminished thereafter (Figure 3B). In weeks 1 to 3, a significantly higher level of IL-4 was detected in the $\mathrm{RGPL}_{\mathrm{L}}$ group, in comparison with the RGP, $\mathrm{BL}$, alum, and $\mathrm{BC}$ groups $(\mathrm{n}=6, P<0.05)$. On days 28 to 42 of the study, the $\mathrm{RGPL}_{\mathrm{M}}$ group showed a significantly higher concentration of IL-4 than the RGP, BL, alum, and BC groups $(\mathrm{n}=6, P<0.05)$.

\section{A}

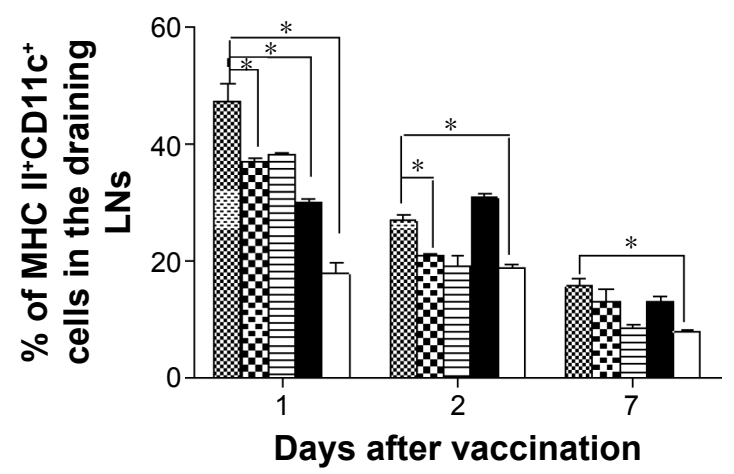

C

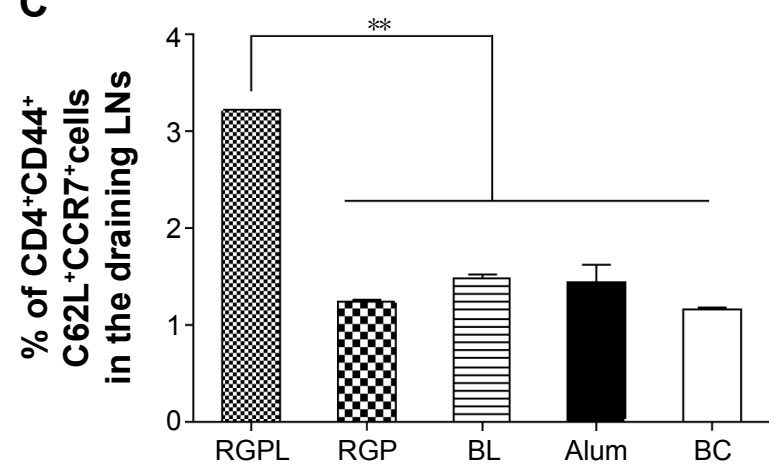

The production of IFN- $\gamma$ was enhanced in a similar pattern to that of IL-4. IFN- $\gamma$ production also revealed significant differences between the groups (Figure 3C). The RGPL ${ }_{M}$ group was determined to have a significantly higher level in comparison with all the other groups $(n=6, P<0.05)$, except for the $\mathrm{RGPL}_{\mathrm{H}}$ and $\mathrm{RGPL}_{\mathrm{L}}$ groups at all the time points investigated.

\section{Antigen transport into draining LNs and memory T-cell responses}

Nanoparticle-antigen formulations administered subcutaneously show differentially affected antigen transport to the draining LNs. In this study, we examined how RGPL affected vaccine potency in terms of activating DCs in the draining LNs. Maturation of DCs is related with enhanced expression of co-stimulatory molecules such as co-stimulatory molecule (CD86) and MHC molecules. MHC II and CD86 expression on DCs in draining LNs was measured by flow cytometry. As shown in Figure 4A and B, RGPL induced significantly higher $\mathrm{MHC} \mathrm{II}^{+} \mathrm{CD} 11 \mathrm{c}^{+}$and $\mathrm{CD}^{+} 6^{+} \mathrm{CD} 11 \mathrm{c}^{+}$

B

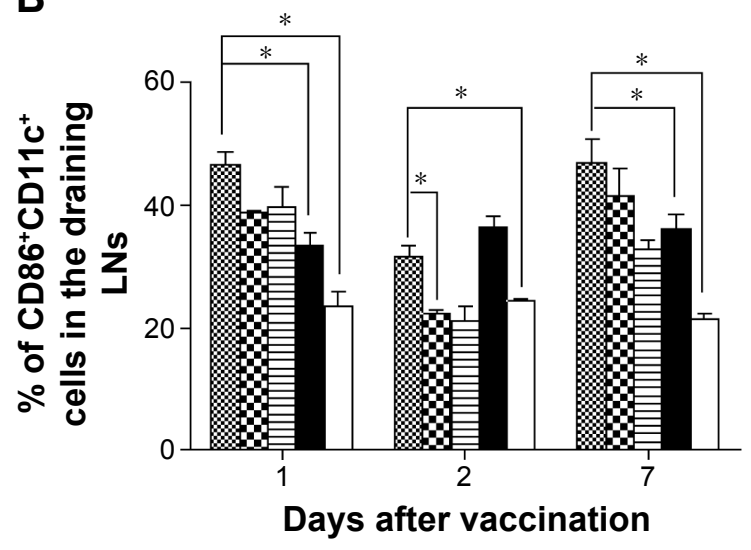

D

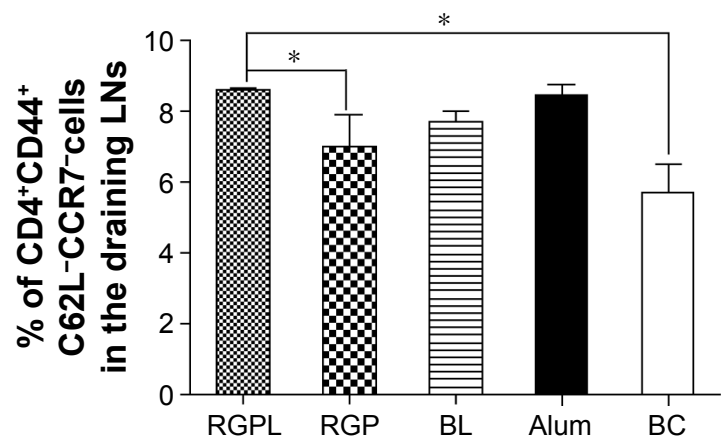

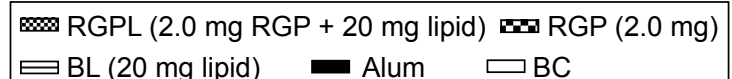



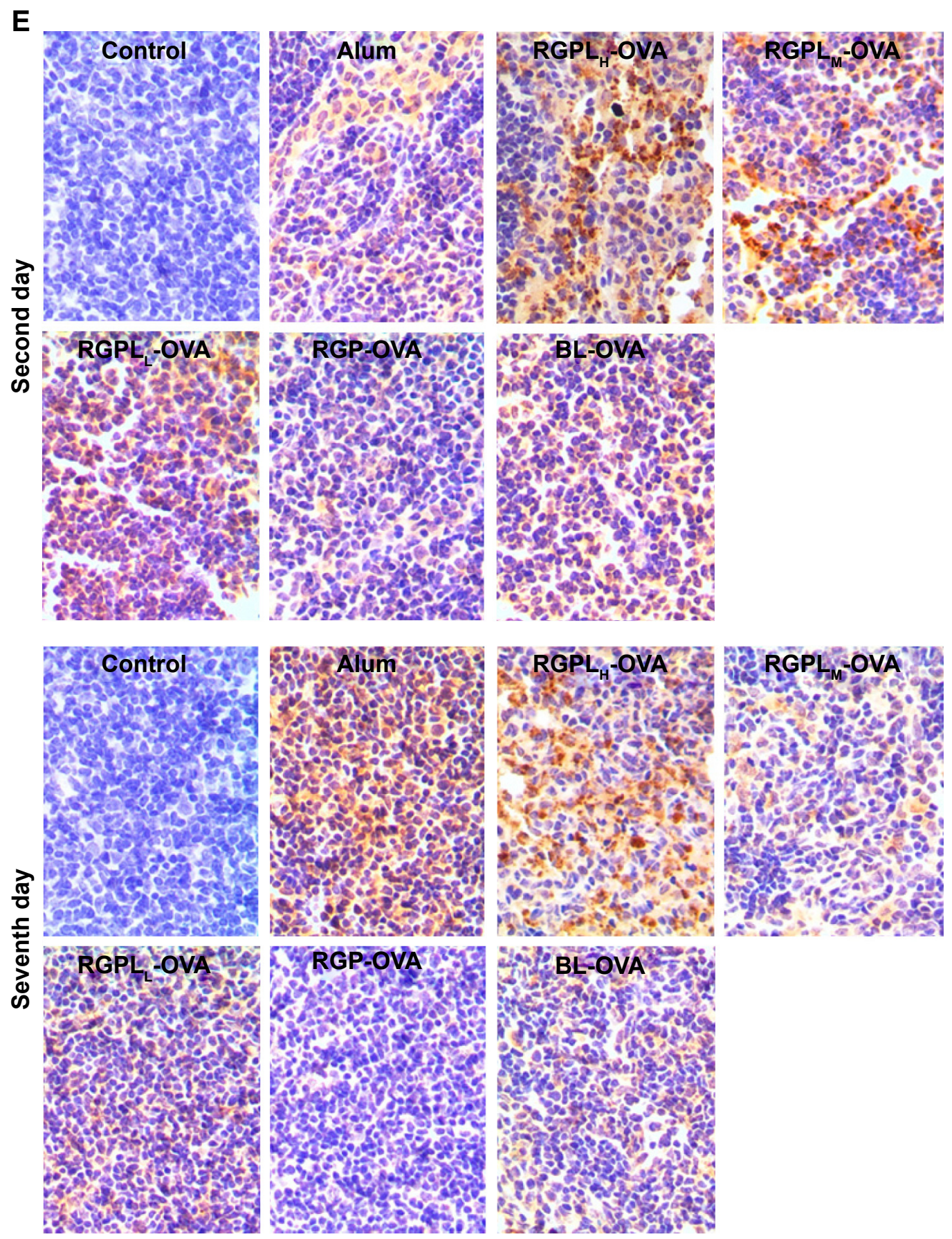

Figure 4 Effects of RGPL on the expression of MHC II and co-stimulatory molecule CD86 on DCs and the percentage of $T_{E M}$ and $T_{C M}$ cells in draining $L N s$.

Notes: C57BL/6 mice $(n=4)$ were subcutaneously vaccinated with different vaccine formulations containing $100 \mu \mathrm{g}$ of OVA encapsulated in RGPL ( $2.0 \mathrm{mg}$ RGP $+20 \mathrm{mg}$ lipid) or mixed with RGP $(2.0 \mathrm{mg})$, alum adjuvant, and BL (20 mg lipid). At the indicated time points (I, 2, or 7 days post-immunization), mice were euthanized and popliteal LNs

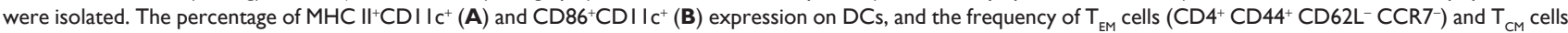
$\left(\mathrm{CD} 44^{+} \mathrm{CD} 44^{+} \mathrm{CD} 62 \mathrm{~L}^{+} \mathrm{CCR7}+\right)$ in the draining $\mathrm{LNs} 7$ days after the second immunization $(\mathbf{C}$ and $\mathbf{D})$ were determined by flow cytometry. Antigen level in $\mathrm{LNs}$ was determined by immunohistochemical assay. (E) Data are representative of four mice in each group. $* P<0.05 ; * * P<0.001$.

Abbreviations: BC, blank control; BL, blank liposomes; DC, dendritic cell; LNs, lymph nodes; OVA, ovalbumin; RGP, Rehmannia glutinosa polysaccharide; RGPL, Rehmannia glutinosa polysaccharide liposome; $\mathrm{T}_{\mathrm{CM}}$, central memory cells; $\mathrm{T}_{\mathrm{EM}}$, effector memory cells.

expression 1 day after immunization than occurred in other groups. At 2 days after the second immunization, the MHC $\mathrm{II}^{+} \mathrm{CD} 11 \mathrm{c}^{+}$and $\mathrm{CD} 86^{+} \mathrm{CD} 11 \mathrm{c}^{+}$expression of the alum group was higher, whereas 7 days after immunization, RGPL elicited the highest $\mathrm{MHC} \mathrm{II}^{+} \mathrm{CD} 11 \mathrm{c}^{+}$and $\mathrm{CD} 86^{+} \mathrm{CD} 11 \mathrm{c}^{+}$ expression, which was mainly due to the liposomal property of controlled release.

To date, two classes of memory Th cells have been distinguished: effector memory cells $\left(\mathrm{T}_{\mathrm{EM}}\right)$ and central memory cells $\left(\mathrm{T}_{\mathrm{CM}}\right)$. The former can display immediate 
effector T-cell function, and the latter are the reservoir of memory and effector T-cells, therefore being responsible for long-term protection. ${ }^{25}$ The result showed that RGPL significantly increased the percentage of $\mathrm{T}_{\mathrm{EM}}$ cells $\left(\mathrm{CD} 4{ }^{+} \mathrm{CD} 44^{+} \mathrm{C} 62 \mathrm{~L}^{-} \mathrm{CCR} 7^{-}\right)$in the draining LNs 7 days after the second immunization (Figure $4 \mathrm{C}$ ). With respect to the percentage of $\mathrm{T}_{\mathrm{CM}}$ cells $\left(\mathrm{CD} 4{ }^{+} \mathrm{CD} 44^{+} \mathrm{C} 62 \mathrm{~L}^{+} \mathrm{CCR} 7^{+}\right)$, the frequency of the cells in the draining LNs was significantly higher for mice immunized with RGPL, as compared to mice immunized with RGP (Figure 4D). Taking these results together, RGPL could have been effectively providing longterm antigen persistence, which resulted in higher expression of both MHC II and CD86 on DCs, as well as a higher frequency of memory T-cells in the draining LNs.

Two days after the second immunization, the most abundant antigen was detected in the LNs of mice immunized with the $\mathrm{RGPL}_{\mathrm{H}}-\mathrm{OVA}$, followed by the mice immunized with RGPL $_{M}-\mathrm{OVA}$ and $\mathrm{RGPL}_{\mathrm{L}}-\mathrm{OVA}$ (Figure 4E, upper panel). Five days later (7 days post-immunization), the most abundant antigen was still detected in the LNs of mice immunized with the $\mathrm{RGPL}_{\mathrm{H}}-\mathrm{OVA}$, followed by alum-OVA (Figure 4E, lower panel). The results are suggestive that $\mathrm{RGPL}_{\mathrm{H}}$ could provide not only adequate antigen exposure in LNs but also long-term antigen persistence.

\section{RGPL were more efficient at promoting DC maturation and improving the activity of mature DCs}

According to Xiang's research, particle size influences the type of cells that are targeted. Nanoparticles in the 20-200 nm range are preferentially taken up by DCs, whereas microparticles $\left(>0.5 \mu \mathrm{m}\right.$ in diameter) are taken up by macrophages. ${ }^{26}$ In the following experiments, the effects of RGPL on DCs in vitro were further investigated.

The upregulation of surface molecules such as CD86, CD80, and MHC II could be viewed as an indicator of maturation of DCs. As shown in Figure $5 \mathrm{~A}-\mathrm{C}$, after co-culture for $48 \mathrm{~h}$, the expression levels of CD86, CD80, and MHC II were significantly increased on DCs stimulated with RGPL $(P<0.001)$. Compared with the RGP group, the percentages of positive fluorescence of CD86, CD80, and MHC II were elevated 2.4-, 1.2- and 1.1-fold in DCs treated with RGPL, respectively. Therefore, RGPL was better than RGP at inducing DC maturation.

Mature DCs have the capacity to induce proliferation of allogenic T-cells, so the abilities of RGPL-treated DCs and RGP-treated DCs were examined. The proliferation of mixed lymphocytes of the DCs treated with RGPL was significantly higher than that of the RGP-treated DCs at the same concentration (Figure 5D).

Mature DCs play a pivotal role in presenting specific antigens to $\mathrm{T}$-cells and initiating the adaptive immune response. To investigate the effects of RGPL on this functional property, DCs treated with RGPL were co-cultured with syngeneic mixed lymphocytes toward OVA. As shown in Figure 5E, mixed lymphocyte proliferative responses stimulated by DCs treated with RGPL were significantly higher than for the T-cells incubated with RGP-treated DCs $(P<0.05)$.

\section{Discussion}

Various natural polymers have been shown to exert strong immunoenhancement properties. R. glutinosa has been used as a traditional Chinese herbal medicine for thousands of years, as proven by the Chinese medical classic "Shennong's Herba". For the purpose of maximizing the desired therapeutic effects of RGP, a proper drug-delivery system was needed to deliver RGP to the target position at a controlled rate. Liposomes have been reported as an adjuvant for vaccine antigens against a large variety of bacteria, viruses, and tumors. ${ }^{11,27,28}$ This adjuvant activity depends on the structural characteristics of the liposomes, which control vesicle fate in vivo, including the mode of antigen interaction with antigen-presenting cells. ${ }^{29}$ In this study, the physical properties of RGPL were investigated. In addition, based on our previous studies, the immunomodulatory effects of this novel delivery system were further researched. In this study, we combined both the advantages of natural medicine and liposomes in order to obtain a vaccine adjuvant that is biocompatible, safe, and has a long duration of action. Results showed that RGPL not only presented a high entrapment rate but also presented as spherical particles with uniform particle size. From the release experiment in vitro, RGPL exhibited excellent drug retention properties.

Experiments in vivo showed RGPL could be an effective nanoparticle-based vaccine adjuvant. First, the proliferation of LPS/PHA-stimulated lymphocytes was compared for the reason that it is the most immediate index reflecting natural immunity. ${ }^{19}$ As shown in Figure 2, RGPL performed significantly better than RGP at the investigated time points. It was indicative that RGP could achieve the desired immunoenhancement effects with a lower dosage after encapsulation in liposomes. In contrast to alum, RGPL sustained high levels of proliferation of LPS/PHA-stimulated lymphocytes during 
A

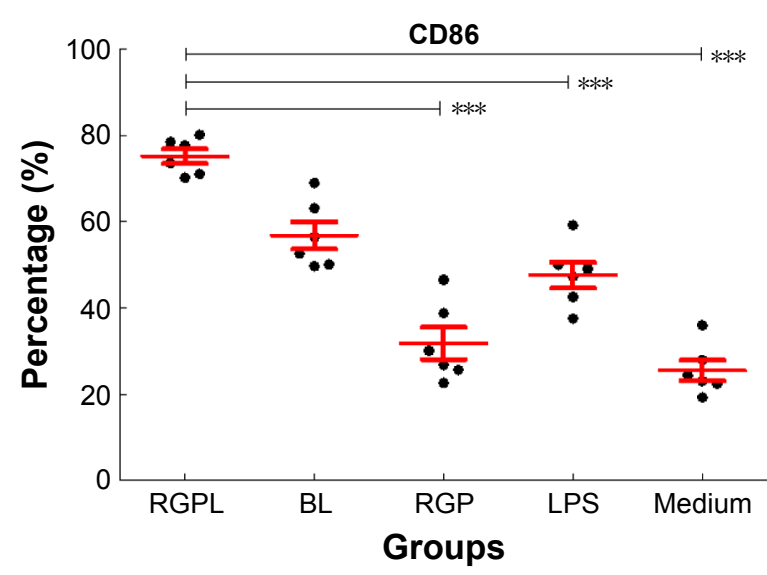

B

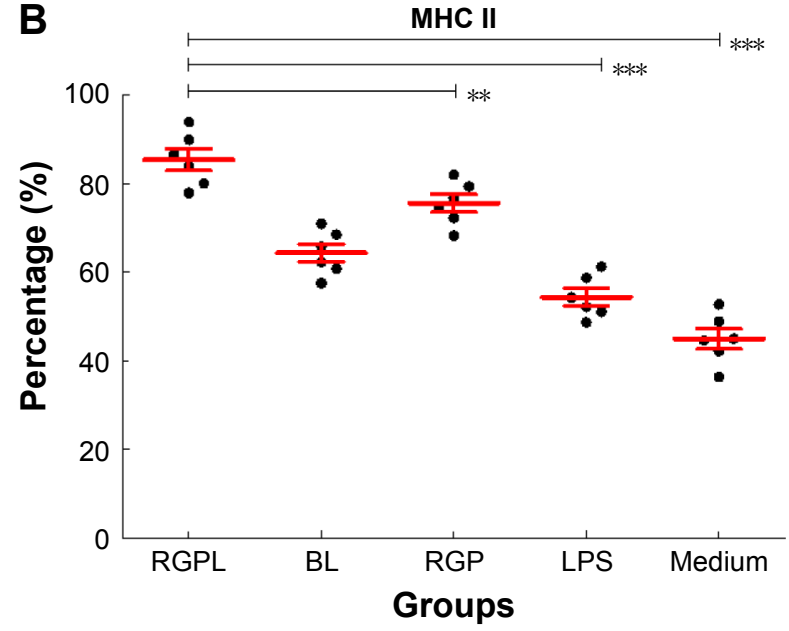

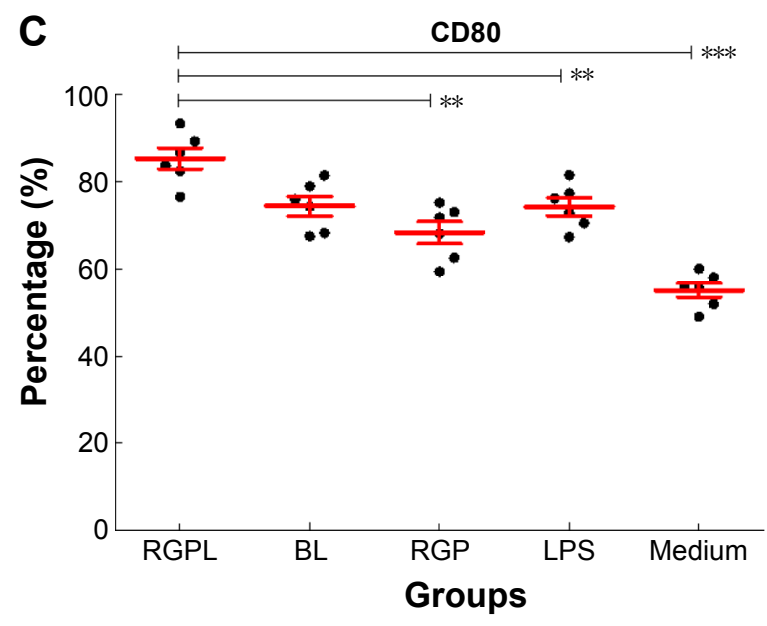
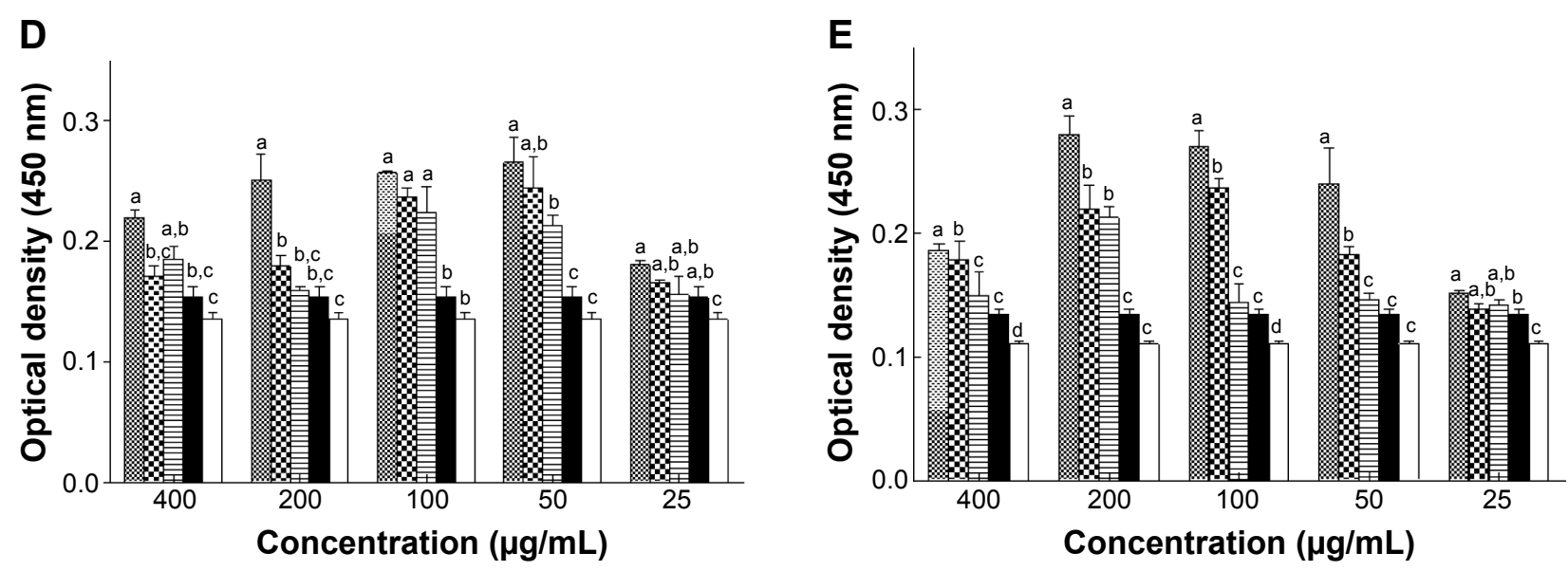

\&GPL RGP $\rightleftharpoons \mathrm{BL} \backsim \mathrm{LPS} \square$ Medium

Figure 5 DCs were stimulated with RGPL, RGP, BL, or LPS, with culture medium as a control.

Notes: (A-C) Phenotypic analysis of DCs. CDI lc ${ }^{+}$bone marrow-derived DCs were exposed to RGPL (200 $\left.\mu \mathrm{g} / \mathrm{mL}\right)$, RGP $(200 \mu \mathrm{g} / \mathrm{mL})$, BL or LPS, or culture medium, for $48 \mathrm{~h}$ and assessed for changes in the expression levels of CD86, CD80, and MHC II. The percentages of CD80, CD86, and MHC II were assessed by flow cytometry. The mean \pm standard errors of the experiment are shown by thick lines $(n=6, * * P<0.01, * * * P<0.00 I)$. (D) Effect of RGPL on the stimulation of the proliferation of T lymphocytes in DCs. ${ }^{a-c}$ Bars under the same concentration without the same superscripts differ significantly $(P<0.05)$. (E) Effect of RGPL on antigen presentation in DCs. a-dBars under the same concentration without the same superscripts differ significantly $(P<0.05)$.

Abbreviations: BL, blank liposomes; DC, dendritic cell; LPS, lipopolysaccharide; OVA, ovalbumin; RGP, Rehmannia glutinosa polysaccharide; RGPL, Rehmannia glutinosa polysaccharide liposome. 
the 6 weeks, which indicated that the RGPLs had a controlled release. Taking the proliferation rate of LPS-stimulated lymphocytes for the $\mathrm{RGPL}_{\mathrm{L}}$ group, for example, at early time points, the proliferation rate of the $\mathrm{RGPL}_{\mathrm{L}}$ group was similar to that of the alum group, whereas during the later period, the $\mathrm{RGPL}_{\mathrm{L}}$ group was significantly superior to the alum group. The controlled release effect made it possible for the high proliferation rate of the lymphocytes to be sustained for a long time.

Levels of OVA-specific IgG and cytokine were measured to further research how RGPL performed in the balance between the Th1 and Th2 type of immune response (Figure 3). The dynamic balance and mutual adjustment between Th1 and Th2 play an important role in maintaining the normal immunological function of organisms. The activation of a Th1 subset is associated with the production of IFN- $\gamma$ and IgG2a, and the generation of cell-mediated immunity, whereas activation of a Th2 subset, with the production of cytokines, such as IL-4, is accompanied by the development of the humoral immune response. ${ }^{30}$ In vivo, IFN- $\gamma$ and IL-4 production were analyzed and the results showed that RGPL promoted higher levels of IFN- $\gamma$ and IL-4 production than RGP did, especially for the $\mathrm{RGPL}_{\mathrm{M}}$ group (Figure 3B and C). RGPL-PCV-2 formulation also elicited strong IgG1 and $\operatorname{IgG} 2$ a responses. ${ }^{18}$ The controlled release of liposome allowed the high level of cytokine and IgG subtype production to be maintained for a prolonged period of time. In addition, results for OVA-specific IgG (Figure 3A) and PCV-2-specific $\operatorname{IgG}^{18}$ exhibited that RGPL could better improve the level of antibodies than RGP. In the first week, there was no significant difference among the groups. At later time points, the IgG titers of RGPL groups were significantly higher than those of RGP and alum groups and were maintained at a high level, especially for the $\mathrm{RGPL}_{\mathrm{H}}$ group. The results reconfirmed the controlled release effect of RGPL and are indicative that RGPL could enhance both Th1-mediated cellular immunity and Th2-mediated humoral immunity.

The frequency of $\mathrm{T}_{\mathrm{EM}}$ and $\mathrm{T}_{\mathrm{CM}}$ cells in the draining $\mathrm{LNs}$ was tested to evaluate whether RGPL could effectively generate immune memory that could rapidly respond to pathogens upon reinfection, which is of pivotal importance for the design of effective vaccines. ${ }^{31}$ Also, drainage to LNs is a prerequisite for effective vaccination. Therefore, in the present work, the way in which RGPL activated the DCs in the draining LNs was investigated. The results were suggestive that RGPL could effectively induce immune memory and higher DC activation.
Liposomes have attracted extensive interest focused on how to increase antigen uptake and promote the activation of DCs, the pacemakers of the immune response. ${ }^{32,33}$ As the most potent specialized APCs that efficiently uptake and process antigen, DCs are often targeted in vaccine design.

DCs are particularly specialized for inducing potent immune responses, owing to their high expression levels of cell surface receptors and a number of complementary molecules that participate in interactions with T lymphocytes. ${ }^{34}$ High levels of MHC molecules that bind and display fragments of antigens for recognition by T-cells with the appropriate T-cell receptors are expressed on the surface of DCs. Antigens taken up by DCs can be processed and presented by both MHC class I and II molecules to specific $\mathrm{CD}^{+}$and $\mathrm{CD}^{+}$ T-cells, respectively, with the former involving a process called cross-presentation or cross-priming. ${ }^{35}$ This process is critical for the induction of cytotoxic T-cell responses, which are important for effective antiviral and antitumor immunity. The present study has demonstrated positive regulation of murine DC maturation by RGPL according to phenotype expression, mixed lymphocyte reaction, and antigen presentation ability. RGPL-treated DCs demonstrated the upregulated expression of maturation markers, such as CD80, CD86, and MHC II, enhanced capacity to induce allogenic $\mathrm{T}$-cell proliferation, and a strengthened antigen presentation function (Figure 5).

\section{Conclusion}

RGPL was found to possess a favorable immune adjuvant activity. RGPL could effectively control drug release. In vitro, they could not only stimulate maturation of DCs but also enhance the function of mature DCs. In vivo, RGPL not only elicited more potent antigen-specific immune responses and maintained these for a longer time but also effectively generated immune memory and induced DC activation in the LNs. Taken together, the results in this study contribute to a deeper understanding of the positive modulation effects of RGPL on the immune system and show a promising future for polysaccharide-based liposome adjuvants as novel vaccine adjuvant systems.

\section{Acknowledgments}

The project was supported by the National Natural Science Foundation of China (grant nos 31372472, 31201880), the Special Fund for Agro-scientific Research in the Public Interest (grant nos 201303046, 201403051), and by the Priority Academic Program Development of Jiangsu Higher Education Institutions. We are grateful to all the other staff at the Institute 
of Traditional Chinese Veterinary Medicine of Nanjing Agricultural University for their assistance with the experiments.

\section{Author contributions}

Yee Huang and DW conceived the idea and designed the Rehmannia glutinosa polysaccharide liposome (RGPL). Yee Huang synthesized and characterized the RGPL. Yee Huang, TQ, Yifan Huang, ZL, and RB designed studies on cells and animals. Yee Huang, TQ, Yifan Huang, ZL, and RB performed the experiments on cells and animals. Yee Huang wrote the paper and all the authors commented on the manuscript. Yee Huang and DW supervised all the studies described in this report. All authors contributed toward data analysis, drafting and revising the paper and agree to be accountable for all aspects of the work.

\section{Disclosure}

The authors report no conflicts of interest in this work.

\section{References}

1. Lindblad EB. Aluminium compounds for use in vaccines. Immunol Cell Biol. 2004;82(5):497-505.

2. Hogenesch H. Mechanism of immunopotentiation and safety of aluminum adjuvants. Front Immunol. 2013;3:406.

3. Talbot RJ, Newton D, Priest ND, Austin JG, Day JP. Inter-subject variability in the metabolism of aluminium following intravenous injection as citrate. Hum Exp Toxicol. 1995;14(7):595-599.

4. Minshall C, Nadal J, Exley C. Aluminium in human sweat. J Trace Elem Med Biol. 2014;28(1):87-88.

5. Li P, Luo Z, Liu P, et al. Bioreducible alginate-poly (ethylenimine) nanogels asan antigen-delivery system robustly enhance vaccine-elicited humoral and cellular immune responses. J Control Release. 2013;168(1): 271-279.

6. Démoulins T, Bassi I, Thomann-Harwood L, et al. Alginate-coated chitosan nanogel capacity to modulate the effect of TLR ligands on blood dendritic cells. Nanomedicine. 2013;9(6):806-817.

7. Kang KH, Kim CH. Inhibitory effect of Rehmannia glutinosa pharmacopuncture solution on $\beta$-hexosaminidase release and cytokine production via immunoglobulin receptor signaling in RBL-2H3 cells. J Acupunct Meridian Stud. 2011;4(4):269.

8. Huang Y, Jiang C, Hu Y, et al. Immunoenhancement effect of Rehmannia glutinosa polysaccharide on lymphocyte proliferation and dendritic cell. Carbohydr Polym. 2013;96(2):516-521.

9. Gregory AE, Titball R, Williamson D. Vaccine delivery using nanoparticles. Front Cell Infect Microbiol. 2013;3:13.

10. Zhao L, Seth A, Wibowo N, et al. Nanoparticle vaccines. Vaccine. 2014; 32(3):327-337.

11. Dobrovolskaia MA, McNeil SE. Immunological properties of engineered nanomaterials. Nat Nanotechnol. 2007;2:469-478.

12. Roldao A, Mellado MC, Castilho LR, Carrondo MJ, Alves PM. Viruslike particles in vaccine development. Expert Rev Vaccines. 2010;9(10): 1149-1176.

13. Patil HP, Murugappan S, ter Veer W, et al. Evaluation of monophosphoryl lipid A as adjuvant for pulmonary delivered influenza vaccine. J Control Release. 2014;174:51-62.

14. Klibanov AL, Shevchenko TI, Raju BI, Seip R, Chin CT. Ultrasoundtriggered release of materials entrapped in microbubble-liposome constructs: a tool for targeted drug delivery. J Control Release. 2010; 148(1):13-17.
15. Watsona DS, Endsley AN, Huang L. Design considerations for liposomal vaccines: influence of formulation parameters on antibody and cell-mediated immune responses to liposome associated antigens. Vaccine. 2012;30(13):2256-2272.

16. Schwendener RA. Liposomes as vaccine delivery systems: a review of the recent advances. Ther Adv Vaccines. 2014;2(6):159-182.

17. Huang Y, Wu C, Liu Z, et al. Optimization on preparation conditions of Rehmannia glutinosa polysaccharide liposome and its immunology activity. Carbohydr Polym. 2014;104:118-126.

18. Huang Y, Liu Z, Bo R, et al. The enhanced immune response of PCV-2 vaccine using Rehmannia glutinosa polysaccharide liposome as an adjuvant. Int J Biol Macromol. 2016;86:929-936.

19. Zhao XJ, Lu Y, Tao Y, et al. Salidroside liposome formulation enhances the activity of dendritic cells and immune responses. Int Immunopharmacol. 2013;17(4):1134-1140.

20. Deng W, Fu M, Cao Y, et al. Angelica sinensis polysaccharide nanoparticles as novel non-viral carriers for gene delivery to mesenchymal stem cells. Nanomedicine. 2013;9(8):1181-1191.

21. Bronte V, Pittet MJ. The spleen in local and systemic regulation of immunity. Immunity. 2013;39(5):806-818.

22. Pan WH, Liu XY, Wang YP. Effects of ginsenoside on immunocompetence of mice splenic lymphocyte and peritoneal macrophage. Res On Spec Local Products. 2001;1:16-19.

23. Elser B, Lohoff M, Kock S, et al. IFN- $\gamma$ represses IL-4 expression via IRF-1 and IRF-2. Immunity. 2002;17(6):703-712.

24. Nakamura T, Kamogawa Y, Bottomly K, Flavell RA. Polarization of IL-4- and IFN-gamma-producing $\mathrm{CD}^{+} \mathrm{T}$ cells following activation of naïve CD4+ T cells. J Immunol. 1997;158(3):1085-1094.

25. Sallusto F, Geginat J, Lanzavecchia A. Central memory and effector memory T cell subsets: function, generation, and maintenance. Annu Rev Immunol. 2004;22:745-763.

26. Xiang SD, Scholzen A, Minigo G, et al. Pathogen recognition and development of particulate vaccines: does size matter? Methods. 2006;40(1):1-9.

27. Pati R, Mehta RK, Mohanty S, et al. Topical application of zinc oxide nanoparticles reduces bacterial skin infection in mice and exhibits antibacterial activity by inducing oxidative stress response and cell membrane disintegration in macrophages. Nanomedicine. 2014; 10(6):1195-1208.

28. Coimbra M, Banciu M, Fens MH, et al. Liposomal pravastatin inhibits tumor growth by targeting cancer-related inflammation. $J$ Control Release. 2010;148(3):303-310.

29. Orr MT, Fox CB, Baldwin SL, et al. Adjuvant formulation structure and composition are critical for the development of an effective vaccine against tuberculosis. J Control Release. 2013;172(1):190-200.

30. Badiee A, Khamesipour A, Samiei A, et al. The role of liposome size on the type of immune response induced in C57BL/6J mice against leishmaniasis: rgp63 as a model antigen. Exp Parasitol. 2012;132(4): 403-409.

31. Pulendran B, Ahmed R. Translating innate immunity into immunological memory: implications for vaccine development. Cell. 2006;124(4): 849-863.

32. Plantinga M, Guilliams M, Vanheerswynghels $M$, et al. Conventional and monocyte-derived $\mathrm{CD} 11 \mathrm{~b}+$ dendritic cells initiate and maintain T helper 2 cell-mediated immunity to house dust mite allergen. Immunity. 2013;38(2):322-335.

33. Powell ND, Mays JW, Bailey MT, Hanke ML, Sheridan JF. Immunogenic dendritic cells primed by social defeat enhance adaptive immunity to influenza A virus. Brain Behav Immun. 2011;25(2011): $46-52$.

34. Mellman I, Steinman RM. Dendritic cells: specialized and regulated antigen processing machines. Cell. 2001;106(3):255-258.

35. Melief CJ. Mini-review: regulation of cytotoxic T lymphocyte responses by dendritic cells: peaceful coexistence of cross-priming and direct priming. Eur J Immunol. 2003;33(10):2645-2654. 


\section{Publish your work in this journal}

The International Journal of Nanomedicine is an international, peerreviewed journal focusing on the application of nanotechnology in diagnostics, therapeutics, and drug delivery systems throughout the biomedical field. This journal is indexed on PubMed Central, MedLine, CAS, SciSearch ${ }^{\circledR}$, Current Contents ${ }^{\circledR} /$ Clinical Medicine,

Journal Citation Reports/Science Edition, EMBase, Scopus and the Elsevier Bibliographic databases. The manuscript management system is completely online and includes a very quick and fair peer-review system, which is all easy to use. Visit http://www.dovepress.com/ testimonials.php to read real quotes from published authors.

Submit your manuscript here: http://www.dovepress.com/international-journal-of-nanomedicine-journal 